$\underline{\text { Research article }}$

\title{
A preliminary survey of knowledge, attitudes and practices regarding rabies in West Bengal, India
}

\author{
Subhabrata Kumar ${ }^{1}$ \\ Sri Lankan Journal of Infectious Diseases 2019 Vol.9(1):79-83 \\ DOI: http://dx.doi.org/10.4038/sljid.v9i1.8233
}

\begin{abstract}
Introduction: This study was conducted to evaluate the knowledge, attitudes and practices (KAP) of patients attending the general outpatient department in Malda Medical College about rabies.
\end{abstract}

Methods: A structured questionnaire was answered by 161 participants. The KAP score was calculated according to the response of the participant.

Results: Compared to adults, children in the 10-15year age group scored much less in all components of rabies prevention and post exposure management.

Conclusion: There was lack of awareness about post exposure prophylaxis of rabies in children. Awareness campaigns especially focusing on children are required to provide better medical care.

Keywords: Rabies, Education, Children, Medical care

\section{Introduction}

Annual deaths caused by rabies in India during 2001-2003 is shown in Table $1 .^{1}$ The Central Bureau of Health Intelligence, Government of India, has published that in the year 2016 a total of eighty six people died due to rabies in India. In West Bengal, forty seven people died due to rabies in the same year. ${ }^{2}$ Malda is located near the Bangladesh border in West Bengal, India.

Most human deaths due to rabies are dog mediated. Human deaths due to rabies are largely seen in rural areas in communities with poor socio-economic status. The main reason for human deaths is lack of awareness among people about the importance of post-exposure prophylaxis. Rabies is a nearly hundred percent vaccine preventable disease. Awareness about rabies and anti-rabies vaccine can make a significant contribution in eliminating rabies. ${ }^{3}$

\footnotetext{
${ }^{1}$ Address for correspondence: Dr Subhabrata Kumar, Assistant Professor, Department of Pharmacology, Malda Medical College and Hospital, West Bengal, India Pin-732101 Telephone +918670095183

Email: subhabrata.kumar@gmail.com (D) https://orcid.org/0000-0002-3619-3524
}

Received 23 October 2018 and revised version accepted 22 March 2019 
Table 1: Annual deaths due to rabies in India (2001-2003)

\begin{tabular}{cc}
\hline Age in years & $\begin{array}{c}\text { Proportion of rabies deaths/ } 1000 \\
\text { deaths }\end{array}$ \\
\hline $0-4$ & 1.1 \\
$5-14$ & 11.5 \\
$15-29$ & 1.6 \\
$30-44$ & 1.9 \\
$45-59$ & 1.4 \\
$60-69$ & 0.5 \\
$70+$ & 0.3 \\
All ages & 1.3 \\
\hline
\end{tabular}

This study has been undertaken to evaluate the knowledge, attitudes and practices of a sample population attending the Outdoor Patient Department of Malda Medical College and Hospital, Government of West Bengal. The study findings can assist in identifying areas which need to be addressed by future health education programs.

\section{Methods}

\section{Study area}

This survey was conducted from April 2017 to January 2018 at the General Outdoor Patient Department (GOPD) of Malda Medical College \& Hospital, West Bengal in India.

\section{Sample size}

Participants were recruited according to the convenient sampling method. One hundred and sixty one patients who attended the GOPD for various health problems were recruited to the study. Participation was voluntary, and the collected data was kept confidential.

\section{Study questionnaire design}

The questionnaire consisted of both open and close-ended questions. Interviewer assisted data collection was done in the participants' native language of Bengali to give a better chance of understanding the content of the question. The questions focused on collecting information about knowledge, attitude and practices with regard to rabies. The questionnaire was pretested.

Questions regarding the knowledge component covered the description of clinical rabies, mode of transmission, outcome, varieties of animals affected by rabies, prevention and control.

Questions related to attitudes covered the outlook towards wound washing, and attending a hospital following exposure.

The practice component included questions on management of a dog bite (washing the wound, going to hospital, taking anti-rabies vaccine, taking tetanus toxoid, taking antibiotics), and observed practice(s) towards a suspect rabid animal or a carcass of a suspect rabid animal.

\section{Scoring system}

Scores were given according to the accuracy and completeness of response by the participants. Scores ranged from zero to two as per nature of the question. Scoring on the knowledge component of post-exposure prophylaxis when exposed to a dog bite is given in Table 2. 
Table 2 Example of the scoring system

\begin{tabular}{lc}
\hline & Marks \\
\hline Post exposure prophylaxis known & 2 \\
\hline Post exposure prophylaxis unknown & 1 \\
Antibiotics and anti-tetanus treatment known & \\
\hline Knowledge about treatment unknown & 0 \\
\hline
\end{tabular}

considered to be a good KAP score.
A score of $60 \%$ or above was considered good for all 3 categories of knowledge, attitudes and practices. The combined score - the KAP score - was calculated by simple addition of the scores from the three components. A KAP score above $60 \%$ was

\section{Data collection}

Participants aged 10 years and above were recruited for the study. The questions were read out to the participants and the responses were noted down securely.

Data analysis

Odds ratio was calculated and $\mathrm{p}$ value $<0.05$ was considered to be statistically significant. The data was analysed using online statistical data analysis software (https://www.medcalc.org)

\section{Results}

A total of 161 participants answered the questions. Of the $161,26 \%$ obtained a KAP score of $>60 \%$ (considered as good) and $74 \%$ had a KAP score of less than $60 \%$ (considered as a poor score).

\section{Socio-demographic characteristics}

Participants resided in the rural areas. The majority of participants belonged to the poor socio-economic group. Of the $161,61 \%$ were Muslims and 39\% Hindus.

The age distribution of the participants is given in Table 3 . Majority (96\%) of the participants were males.
Table 3 Age distribution of participants

\begin{tabular}{cc}
\hline Age in years & $\%$ \\
\hline $10-15$ & 7 \\
$16-30$ & 42 \\
$31-50$ & 31 \\
$>51$ & 20 \\
\hline
\end{tabular}

The distribution of knowledge about rabies is shown in Table 4 and that on attitudes and practices in Table 5.

Table 4: Knowledge about rabies

\begin{tabular}{lll}
\hline Knowledge component & Yes & No \\
\hline $\begin{array}{l}\text { Knows about rabies as a } \\
\text { disease }\end{array}$ & 42 & 119 \\
\hline Rabies is transmitted by dogs & 144 & 17 \\
\hline $\begin{array}{l}\text { Rabies is transmitted by other } \\
\text { animals }\end{array}$ & 127 & 34 \\
\hline Rabies is always fatal & 106 & 55 \\
\hline
\end{tabular}

As shown in Table 4, most of the participants knew that rabies spreads through a dog bite $(n=144)$. Although the majority knew that rabies was invariably fatal, 55 of the 161 participants were not aware of this fact.

There was a significant association of the management of dog bite score with age (Odds ratio: $0.0648,95 \%$ confidence interval: $0.0081-0.5198, \mathrm{Z}$ statistics: 2.576 , significance level $\mathrm{p}=0.0100)$. The result is significant at $\mathrm{p}<0.05$. Children $(10-15$ years $)$ scored significantly 
less as compared to participants older than 15 years in management of dog bite (Table 6).

Table 5: Attitudes and practices towards rabies

\begin{tabular}{lcc}
\hline Component & Yes & No \\
\hline $\begin{array}{l}\text { Hospital presentation and } \\
\text { post exposure prophylaxis } \\
\text { following a dog bite. }\end{array}$ & 92 & 69 \\
\hline $\begin{array}{l}\text { Get the suspect rabid } \\
\text { animal killed }\end{array}$ & 125 & 36 \\
\hline
\end{tabular}

Table 6: Comparison between children (10-15 years) and participantsolder than 15 years in management of dog bite

\begin{tabular}{lcc}
\hline & Good & Poor \\
\hline $\begin{array}{l}\text { 10-15 years } \\
\begin{array}{l}\text { Participants older } \\
\text { than15 years }\end{array}\end{array}$ & 91 & 10 \\
\hline
\end{tabular}

\section{Discussion}

Rabies is a significant health burden in India. ${ }^{2}$ Dog mediated transmission is the most common cause of human rabies which was known by 144 of the 161 participants. Rabies is always fatal once symptoms of the disease start to occur and the majority of the participants $(\mathrm{n}=106)$ knew this. However, rabies is a preventable disease. A large number of clinical studies have been conducted worldwide to highlight this key aspect. ${ }^{4,5,6,7,8}$

Global statistics have shown that $90 \%$ of human deaths due to rabies occur in children. Deaths in children occur because they like playing with dogs and lack awareness about transmission of rabies by dogs. Children also try to hide dog bites and scratches for fear they might be reprimanded by their parents. To achieve the Rabies ZERO by 2030 target, the Ministry of Health and Family Welfare, Government of India has implemented the National Rabies Control Programme. One of the important aspects stressed in this programme was the education of children to prevent dog bites and encouraging parents to praise a child who tells them about a dog bite or scratches. The guidelines also asked people to avoid treating the wounds with indigenous products like turmeric, soil etc. Importance of immediate medical care after a dog bite was advocated throughout the National Rabies Control Programme. ${ }^{10}$

Studies conducted in school children have shown improvements in knowledge, attitudes and practices towards rabies management among them. ${ }^{11,12}$ This study conducted in Malda District, West Bengal can improve the awareness about rabies in children and provide better medical care.

Limitation of this study: This study showed that as far as knowledge about post exposure prophylaxis of rabies is concerned, children below 15 years scored significantly less as compared to other age groups. However, the number of children who participated in the current study was limited. A study involving a larger number of children is required to confirm these results. 


\section{Conclusion}

There was lack of awareness about post exposure prophylaxis of rabies in children as compared to older age groups. As lack of knowledge and awareness contributes to continuing exposure to rabies, we recommend an intentional programme to sensitize the population about the risk factors for rabies and post exposure management. The use of electronic media and other methods to specifically target children is indicated if the results of our study are confirmed in a larger study.

Acknowledgement: All the participants, my colleagues and my family members

\section{Conflict of Interest: Nil}

Ethical statement: The study was approved by the Institutional Ethics Committee, Malda Medical College, Malda, Government of West Bengal.

\section{References:}

1. Suraweera W, Morris SK, Kumar R, et al. Deaths from symptomatically identifiable furious rabies in India: A nationally representative mortality survey. PLoS Negl Trop Dis 2012 6(10): e1847. doi:10.1371/journal.pntd.0001847

2. Central Bureau of Health Investigation, Government of India. National Health Profile 2017 Part -1. State/UT wise Cases and deaths due to rabies in India, 2016. http://cbhidghs.nic.in accessed March 2018

3. World Health Organization: Rabies Home Page on internet. Available from: www.who/int/rabies/en.accessed March 2018

4. JT Muthunuwan, AGKH Ganhewa, HDSG Perera et al. Preliminary survey on knowledge, attitude and practice regarding rabies. Sri Lankan Journal of Infectious diseases 2017; 7(1):38-46 doi: http://doi.org/10.4038/sljid.v7il.8133

5. Gino C. Matibag, Yoshihide Ohbayashi, Koji Kanda, et al. A pilot study on the usefulness of information and education campaign materials in enhancing the knowledge, attitude and practice on rabies in rural Sri Lanka. J Infect Developing Countries 2009; 3(1):55-64. doi:https://doi.org/10.3855/jidc.106

6. Sambo M, Lembo T, Cleaveland S et al. Knowledge, Attitudes and Practices (KAP) about rabies prevention and control: A community survey in Tanzania. PLoS Negl Trop Dis. 2014 ;8(12): e3310.doi:10.1371/journal.pntd.0003310

7. Tripathy RM, Satapathy SP, Karmee N. Assessment of knowledge, attitude and practice regarding rabies and its prevention among construction workers: a cross-sectional study in Berhampur, Odisha. Int J Res Med Sci 2017;5:3970-5. doi: http://dx.doi.org/10.18203/2320-6012.ijrms20173964

8. Suhasani Tandon, S.K. Kotwal, M.A. Malik et al. A community based survey on rabies control and prevention using KAP in Jammu, India. Journal of Animal Research. 2017;7(6):1019-1028. doi: http://dx.doi.org/10.5958/2277-940X.2017.00153.X

9. Medcalc Software. Available from https://www.medcalc.org [Assessed on March 2019]

10. National Health Portal, India . Available at www.nhp.gov.in/world-rabies-day. Accessed on March 2018

11. Hossain M. Study on knowledge, attitude \&practice about rabies \&pet animals among school children in Bangladesh. J Microbiol Exp 2017; 4(1):00103

doi: 10.15406/jman.2017.04.00103

12. Burdon Bailey JL, Gamble L, Gibson AD et al.A rabies lesson improves rabies knowledge amongst primary school children in Zomba, Malawi. PLoS Negl Trop Dis2018: 12(3):e0006293. doi:https://doi.org/10.1371/journal.pntd.0006293 